\title{
The Role of Moral Intelligence and Identity Styles in Prediction of Mental Health Problems in Healthcare Students
}

\author{
Mahbobeh Faramarzi' ${ }^{1}$, Kolsoom Jahanian ${ }^{2 *}$, Mohamadreza Zarbakhsh ${ }^{3}$, \\ Sirous Salehi ${ }^{3}$, Hajar Pasha ${ }^{4}$ \\ ${ }^{1}$ Social Determinants of Health Research Center, Psychiatric Department, Babol University of Medical Sciences, \\ Babol, Iran \\ ${ }^{2}$ Counseling Clinic, Babol University of Medical Science, Babol, Iran \\ ${ }^{3}$ Department of Psychology, Tonekabon Branch, Islamic Azad University, Tonekabon, Iran \\ ${ }^{4}$ Fatemeh Zahra Infertility and Reproductive Health Research Center, Babol University of Medical Sciences, \\ Babol, Iran \\ Email: Mahbob330@yahoo.com, ${ }^{*}$ jahanian.eli33@yahoo.com, rzarbakhsh@yahoo.com, \\ Sirous.salehi@gmail.com, pashahajar@yahoo.com
}

Received 28 December 2013; revised 31 January 2014; accepted 10 February 2014

Copyright (C) 2014 by authors and Scientific Research Publishing Inc.

This work is licensed under the Creative Commons Attribution International License (CC BY). http://creativecommons.org/licenses/by/4.0/

(c) (i) Open Access

\section{Abstract}

Background: Assessment of healthcare students' mental health problems is an important aspect of health promotion. This study examined the roles of moral intelligence (MI) and identity styles in prediction of mental health problems in healthcare students. Methods: In a correlation study, two hundred healthcare students (100 girls, 100 boys) of Medicine, Density, and Paramedicine Colleges of Bobol University of Medical Sciences were selected. The subjects filled out three questionnaires; General Health Questionnaire (GHQ-28), Moral Competency Inventory (MCI), and Identity Style Inventory (ISI), and General Health Questionnaire (GHQ-28). Pearson correlation, multivariate analysis variance model (MANOVA), and multivariate regression used to analyze the data. Results: Boys and girls did not have a meaningful difference in the mean of total GHQ, MCI, normative and informational identity. Girls had significantly higher mean level of diffused-avoidant identity than boys. There was a positive and significant relationship between moral intelligence, normative identity and mental health problems of students. Also, there was a negative relationship $(p<0.05)$ between diffused-avoidant identity and mental health problems of students. Moral intelligence, informational and normative identity predicted $25.8 \%$ of the variance in mental health problems for girls' students. Normative and diffused-avoidant identity predicted $21.6 \%$ of the variance in mental health problems for girls' students. Conclusions: This study demonstrated that moral intelligence and identity status contributed to the mental health problems of health-

\footnotetext{
${ }^{*}$ Corresponding author.
} 
care students. University administrators should adopt strategies that strengthen the moral intelligence and identity maturity associated with university students' mental health.

\title{
Keywords
}

\author{
Mental Health Problems; Moral Intelligence; Identity Style
}

\section{Introduction}

Mental health is defined as an individual's state of well-being when he realizes his abilities, has the ability to cope with the normal stresses of life, able to work productively and fruitfully and can contribute to his community [1]. University students are more at risk of the developing mental health problems or disorders compared with their peers of similar age group in the general population [2]. The numbers of cases documenting mental health problems among university students are the increase each year [3]. It is also true that studies concerning the link between students' mental health problems and their psychology are limited. Several predictors of mental health in university students have been pointed out in previous literature, demographic backgrounds such as age and gender [4], loneliness [5], academic field and academic year [6], personality traits [7], optimism, health, values [8], religiousness [9], and emotional intelligence [10]. However, a review of literature on the subject reveals that information regarding mental health problems and moral intelligence is not available.

Doug Lennick and Fred Kiel (2011) defined moral intelligence as, "the mental capacity to determine how universal human principles should be applied to our values, goals, and actions” [11]. Borba (2001) defined moral intelligence as the capacity to understand right from wrong, to have strong ethical convictions and to act on them to behave in the right and honorable way. The construct of moral intelligence consists of integrity (harmony between what we believe and how we act), responsibility (taking personal responsibility, admitting mistakes and failures, and embracing responsibility for serving others), forgiveness (letting go of one's own mistakes and letting go of others' mistakes) and compassion (caring about others which shows our respect for others) [12]. The aim of moral intelligence is to make the interaction between the environment and the individual functional [13].

Little research is available regarding the moral intelligence. Although there have been no published investigations in relationship of moral intelligence and mental health problems few research reported the association of metal health and constructs of moral intelligence like responsibility and forgiveness. A recent report supported that moral responsibility could play a vital role in healthcare provision [14]. Some researches supported the influence of forgiveness on the both the psychological and physical health of individuals [15]-[17]. There has also been increasing interest in the relationship between compassion and mental health outcomes. Mac Beth and Gumley (2012) in a meta-analysis of the association between self-compassion and psychopathology reported that compassion is an important explanatory variable in understanding mental health and resilience [18].

Identity formation is increasingly discussed as having a potential role in healthcare students, both for personal mental health and professional practice. The research reviewed suggests that varying degrees of self-identity development have implications for the differences in persons' mental health [19]. In particular, Berzonsky (2002) identified three identity-processing orientations that were defined by exploration and commitment: diffuse-avoidant, normative, and informational identity. Individuals with a diffuse-avoidant orientation possess low levels of self-exploration and commitment; when faced with challenging situations, these individuals are reluctant to confront personal problems and often procrastinate making decisions. Individuals who have a normative orientation possess high levels of commitment and low levels of self-exploration; those with this orientation tend to be closed-minded and focus primarily on the standards and expectations of significant others. Finally, individuals with an informational identity orientation possess a high level of self-exploration and either high or low levels of commitment; these adolescents are introspective and actively seek out, process, and utilize self-relevant informational identity [20].

Development of moral intelligence seems to accompany the development of identity. Individuals high in identity (identity achievement) tend to be functioning at high levels of moral reasoning, while subjects lower in 
identity (identity diffusion) are found to tie at low levels [21]. There is no published study that describes the role of moral intelligence and identity styles in predicting of mental health problems of healthcare university students. The aim of this research was to find and explore the relationship between moral intelligence and identity styles with general health report among healthcare university students.

\section{Methodology}

\subsection{Data Collection}

The descriptive-analytical study was conducted with three groups of healthcare students (medicine, density, and paramedicine) of Babol University of Medical Sciences in autumn and terms of the 2012-13 academic years. Two hundred students (100 female, 100 male) with a mean age of $20.6(S . D=5.0)$ participated in the study. No exclusion criteria were applied but students were self-selecting as participation was entirely voluntary. A multistage cluster sampling was utilized to recruit the respondents based on their field and year of study.

The researcher distributed three questionnaires to the respondents during class hours. Permission was sought from the deans of faculty to distribute the questionnaires to targeted respondents. The researcher also gave a brief explanation regarding the purpose of the study, reminded their respondents of their rights to not answer any question and how to fill in the questionnaires. The respondents were also told that their response would be treated with utmost confidentiality. All students asked to complete three questionnaires. One questionnaire collected demographic informational identity, one measure of moral intelligence and one measure of identity styles. The questionnaire took only 40 minutes to complete.

\subsection{Measures}

A general demographic characteristics questionnaire was used to obtain respondents' informational identity such as age, gender, field of study and year of study.

General Health Questionnaire (GHQ-28): GHQ-28 was provided by Goldberg \& Hiller (1972), and standardized by Homan (1996), on Bachelor's Degree students of Tarbiat Moallem University of Tehran [22]. The scale is the most widely used screening instrument for detecting minor psychiatric disorders in community samples. The GHQ offers a continuous measure of psychological distress or current mental health problems status that captures the probability of having a current disorder, and also predicts imminent onsets. The scale consists of 28 items and was rated on the 4-point Likert scale, ranging from 1 (better than usual) to 4 (much less than usual). The instrument has four sub-scales; somatic, anxiety \& sleep disorder, impairment in social functioning, and depression symptoms. From sum of scores of these 4 sub-scales, one total score will be obtained for health of individual [23]. It should be noted that high scores in this test indicates the high mental health problems individual, therefore in description of correlations, this matter should be considered.

Moral Competency Inventory (MCI): The MCI developed by Lennick's and Kiel (2005) sets out to measure ten competencies within a moral framework. The competencies are: 1) acting consistently with principles, values and, beliefs; 2) telling the truth; 3) standing up for what is right; 4) keeping promises; 5) taking responsibility for personal choices; 6) admitting mistakes and failures; 7) embracing responsibility for serving others; 8) actively caring about others; 9) ability to let go of one’s own mistakes; 10) ability to let go of others' mistakes. The first four of the competencies in the MCI claim to measure integrity. Responsibility is measured in competencies five through seven. Compassion is measured in eighth competency. The two end of the competencies in the MCI claim to measure forgiveness. A five point Likert-like scale $(1=$ Never; $2=$ Infrequently; 3 = Sometimes; $4=$ In most situations; and 5 = In all situations) remains constant through the forty question instrument. Additive scores of 90 to 100 are considered very high, 80 to 89 high, 60 to 79 moderate, 40 to 59 low, 20 to 39 very low [24] Martin (2010) reported an acceptable validity for MCI. Cronbach alpha varied 0.65 - 0.84 for 10 subscales [25].

Identity Style Inventory: Forty-item Identity Style Inventory (ISI) developed by Berzonsky (1992) was employed to assess three identity-processing styles [26]. Respondents completed items on a Liker scale (1 = strongly disagree; 5 = strongly agree). A valid Persian version of the ISI was used in this study [27].

\subsection{Ethical Approval}

Ethical approval was granted by the Department of psychology sciences Ethics Committee at Islamic Azad 
University Tonekabon Branch and by the Medical Ethics Committee at Babol University of Medical Sciences.

\subsection{Analysis}

Data was analyzed using the Statistical Package for the Social Science (SPSS version 16). Multivariate Analysis of variance (MANOVA) used to compare differences in moral intelligence and identity styles for men and women. Stepwise model of multiple regression analysis was used to assess correlation between intelligence and identity styles with mental health problems in girls and boys. $\mathrm{P}<0.05$ was considered for level of significant.

\section{Results}

The result of between group of MANOVA (means and standard deviations for identity styles, general health, moral intelligence, and their subscales) showed in Table 1. Two groups did not have a meaningful difference in the mean of total GHQ and GHQ dimensions. Girls and boys did not have a meaningful difference in all of moral intelligence dimensions except "actively caring about others". Girls had significantly higher mean level of compassion subscale than boys $(p<0.05)$.The identity styles dimensions were not different in boy and girls except for diffused identity. Girls had significantly higher mean level of diffused-avoidant identity than boys $(\mathrm{P}<0.05)$.

Table 2 shows bivariate correlations between moral intelligence, identity styles, and general health. It can be concluded that there was a negative and significant relationship between MI and all of the GHQ dimensions. Simirially, there was a negative and significant relationship between normative identity style and all of the GHQ dimensions. There was no significant relationship between informational identity style and GHQ dimensions. Also, there was a positive and significant relationship between informational identity, normative, and commitment identity styles and MI. Negative relationship between MI and diffused-avoidant identity style was significant.

Multiple regression analyses were performed to examine the relationship of MI, identity styles, and GHQ. A simultaneous multiple regression analysis was conducted to determine if MI and identity styles were predictive

Table 1. Mean of variables in girls and boys university students.

\begin{tabular}{|c|c|c|c|c|c|}
\hline \multirow{2}{*}{ Variables } & \multicolumn{2}{|c|}{ Girls } & \multicolumn{2}{|c|}{ Boys } & \multirow{2}{*}{ P-value } \\
\hline & Mean & SD & Mean & $\mathrm{SD}$ & \\
\hline \multicolumn{6}{|l|}{ Identity } \\
\hline Information & 36.56 & 5.69 & 36.60 & 5.71 & 0.960 \\
\hline Normal & 33.13 & 4.80 & 32.74 & 5.06 & 0.577 \\
\hline Diffused & 28.19 & 5.34 & 26.55 & 5.30 & 0.031 \\
\hline Commitment & 37.61 & 6.40 & 38.58 & 5.58 & 0.255 \\
\hline \multicolumn{6}{|l|}{ GHQ } \\
\hline Somatic & 4.46 & 3.52 & 4.35 & 3.58 & 0.795 \\
\hline Anxiety & 4.75 & 4.37 & 5.05 & 4.50 & 0.634 \\
\hline Social function impairment & 7.42 & 3.06 & 7.14 & 2.97 & 0.513 \\
\hline Depression & 2.72 & 4.84 & 3.06 & 4.78 & 0.618 \\
\hline Total scores & 19.37 & 13.61 & 19.60 & 13.32 & 0.904 \\
\hline \multicolumn{6}{|l|}{ Moral Competency Inventory (MCI) } \\
\hline Acting consistently with principles & 7.44 & 1.16 & 7.25 & 1.28 & 0.276 \\
\hline Telling the truth & 7.53 & 0.94 & 7.33 & 0.99 & 0.146 \\
\hline Standing up for what is right & 6.74 & 1.13 & 6.96 & 1.18 & 0.191 \\
\hline Keeping promises & 7.69 & 1.10 & 7.42 & 0.98 & 0.075 \\
\hline Taking responsibility for personal choices & 7.25 & 1.10 & 7.20 & 1.09 & 0.748 \\
\hline Admitting mistakes and failures & 7.42 & 1.01 & 7.26 & 1.12 & 0.292 \\
\hline Embracing responsibility for serving others & 7.04 & 1.07 & 6.90 & 1.10 & 0.366 \\
\hline Actively caring about others & 7.58 & 1.11 & 7.24 & 1.17 & 0.34 \\
\hline Ability to let go of one's own mistakes & 7.26 & 1.10 & 7.29 & 1.19 & 0.854 \\
\hline Ability to let go of others' mistakes. & 7.02 & 1.19 & 7.20 & 1.10 & 0.295 \\
\hline Total scores & 72.99 & 8.37 & 72.07 & 8.12 & 0.431 \\
\hline
\end{tabular}


Table 2. Pearson correlations of identity styles, moral intelligence and mental health problems.

\begin{tabular}{|c|c|c|c|c|c|c|c|c|c|}
\hline Variables & 1 & 2 & 3 & 4 & 5 & 6 & 7 & 8 & 9 \\
\hline \multicolumn{10}{|l|}{ 1-Information } \\
\hline 2-Normal & 0.530 & & & & & & & & \\
\hline 3-Diffused & -0.49 & -0.040 & & & & & & & \\
\hline 4-Commitment & $0.375^{* *}$ & $0.612^{* *}$ & $-.294^{* *}$ & & & & & & \\
\hline 5-Somatic & -0.80 & $-0.309^{* *}$ & $0.208^{* *}$ & $-0.445^{* *}$ & & & & & \\
\hline 6-Anxiety & -0.072 & $-0.318^{* *}$ & 0.126 & $-0.410^{* *}$ & $0.700^{* *}$ & & & & \\
\hline 7-Social & -0.005 & $-0.238^{* *}$ & 0.080 & $-0.344^{* *}$ & $0.533^{* *}$ & $0.466^{* *}$ & & & \\
\hline 8-Depression & -0.081 & $-0.359^{* *}$ & 0.137 & $-0.454^{* *}$ & $0.624^{* *}$ & $0.758^{* *}$ & $0.536^{* *}$ & & \\
\hline 9-Total GHQ & -0.75 & $-0.368^{* *}$ & $0.164^{*}$ & $-0.492^{* *}$ & $0.838^{* *}$ & $0.900^{* *}$ & $0.711^{* *}$ & $0.902^{* *}$ & \\
\hline 10-Total MCI & $0.454^{* *}$ & $0.509^{* *}$ & $-0.142^{*}$ & $0.505^{* *}$ & $-0.289^{* *}$ & $-0.285^{* *}$ & $-0.268^{* *}$ & $-0.283^{* *}$ & $-0.331^{* *}$ \\
\hline
\end{tabular}

of mental health problems for the all healthcare students. The analysis of variance (ANOVA) results from the overall regression equation were statistically significant, $\mathrm{F}(4,195)=13.4, p<0.001$. The model summary from the regression analyses showed that the set of predictor variables accounted for significant variance in the dependent variable, mental health problems, with a moderate effect size (adjusted $R 2=0.199$ ).

Further analyses of within-group differences was conducted to determine if MI and identity styles differentially predicted mental health problems for boys and girls students. Therefore, two step by step regression methods (one for boys, another for girls) have been applied. To do this, variable of GHQ as criterion and identity dimensions (informational identity, normative, diffused-avoidant styles), moral intelligence (total MCI) as predictor variable have entered to this model. The results are presented in Table 3.

For the girls healthcare students, the regression equation was statistically significant, $\mathrm{F}(4,95)=8.3, p<0.001$, with the model accounting for $25.8 \%$ of the variance in mental health problems (adjusted $R 2=0.227$ ). MI and normative identity were negative predictors of mental health problems in girls' students. Higher Moral intelligence and normative style scores were associated with lower scores on mental health problems. Informational identity style was positively associated with mental health problems. Results indicate that the strongest predictor of mental health problems was moral intelligence in girls students $(\beta=-0.375, p<0.01)$.

For the boys healthcare students, the regression equation was statistically significant, $\mathrm{F}(4,95)=6.5, p<0.001$, with the model accounting for $21.6 \%$ of the variance in mental health problems (adjusted $R 2=0.183$ ). Normative identity was negative predictor of mental health problems in boys' students. Higher normative identity scores were associated with lower scores on mental health problems.

Diffused-avoidant identity was positively associated with mental health problems. Results indicate that the strongest predictor of mental health problems was diffused-avoidant identity in boys students $(\beta=0.195, p<$ 0.05).

\section{Discussion and Conclusions}

This study showed that there was no difference between girls and boys of healthcare students in moral intelligence, identity status, and mental health problems. However, for the interpersonal component, girls scored higher in levels of diffused-avoidant and compassion. Lewis (2003) reported that there was no difference between men and women in overall identity scores [28]. However, this finding contradicted with a previous study found that girl students scored higher than men in formational and normative Identity. Also, boy students scored higher than girls in diffused-avoidant Identity [29].

The results indicate that there is a negative and significant correlation between moral intelligence and mental health problems. In the other word, it can be cited that increasing the scores of MI will decrease in all subscales of mental health problems. Although some researches indicated that MI was highly associated with leadership effectiveness [30] [31], no published research reported the relationship of moral intelligence and mental 
Table 3. Results of Enter model of regression analysis in girls and boys university students.

\begin{tabular}{ccccc}
\hline \multirow{2}{*}{ variables } & \multicolumn{2}{c}{ Girls } & \multicolumn{2}{c}{ Boys } \\
\cline { 2 - 5 } & Standardized Beta & significant & Standardized Beta & significant \\
\hline Information & 0.365 & 0.001 & 0.084 & 0.446 \\
normal & -0.351 & 0.003 & -0.0366 & 0.002 \\
Diffused & 0.075 & 0.113 & 0.195 & 0.037 \\
moral & -0.375 & 0.001 & -0.120 & 0.265 \\
\hline
\end{tabular}

$\mathrm{R}^{2}$ Girls: $0.258 \mathrm{P}=0.000 . \mathrm{R}^{2}$ Boys: $0.216 \mathrm{P}=0.000$.

health problems. However, little research reported the association of metal health and structures of moral intelligence. Quenstedt-Moe and popkess (2012) suggested that there were important relationships between forgiveness and psychological and physical health in Christian women [16]. Lawler (2005) in assessment of the relationship forgiveness and health reported that forgiveness could lead to fewer physical symptoms, reduction in negative affect and reduction in stress [15]. Also, research supported that compassion would be associated with improved wellbeing and reduced emotional distress [32]. In addition, personal responsibility should play an important role in health behavior [14].

Results indicated that normative identity and commitment were inversely related with mental health problems. Also, there was a positive and significant correlation between and diffused-avoidant identity and mental health problems. The results of this research were in the same line with performed researches by Shokri Tajick Esmaeeli (2007), Aghaei (2012), and Abdizarrin (2010) which indicated that mental health problems were in relationship with low level of identity status [19] [33] [34]. Berzonsky (2002) by designing a research along this research concluded that significant attributes of people who had anxious identity would have low process of data and solving matters that approximately is along this scheme's result [35]. Some studies supported that there was a positive correlation between metal health and commitment [34] [36].

For the girls of healthcare students, the results of regression have indicated that informational identity, normative identity, and moral intelligence were predictors of mental health problems. Although no study had previously been published to assess the moral intelligence in girls of healthcare students, few studies reported that a person who had a good intelligence could cope with the facts well than others [37]. A study reported that normative identity and commitment were the predictors of mental health problems in girl students [34].

The results indicated that normative and diffused-avoidant identities were predictors of mental health problems for the boys of healthcare students. Previous studies confirmed that identity processing style was associated with mental health. Hardly (2012) found that identity maturity and moral identity predicted all of the health outcomes. Also identity maturity and moral identity interacted in predicting mental health problems and psychological well-being [38].

In particular, a diffuse-avoidant style seems to be associated with mental disorders, such as affective disorders [39], neuroticism [40], conduct disorders [41], and problems with alcohol [42].

How are higher levels of moral intelligence associated with lower mental problems in healthcare students? It is unclear. However, it seems that moral intelligence may protect people from stress and lead to better adaptation. Scientific research supports the importance of moral intelligence for individuals. Moral intelligence is the "central intelligence” for all humans. It's because moral intelligence directs our other forms of intelligence to do something worthwhile. Moral intelligence gives our life purpose. In general, moral intelligence increases each actor's survival chances and wellbeing [11]. Besides, moral intelligence can include recognizing problems, setting goals, deciding on what is the right thing to do, taking action and persevering [12]. The studies show that moral intelligence is highly associated with persons' effectiveness [11] [12]. Such increased support may help protect these people from mental health problems such as depression, anxiety, and social impairment.

There are a number of limitations in our study that warrant caution against generalizing from our results. First, data collection has been performed by questionnaires. There is no certainty about accuracy and truth of responses. Performing research by applying questionnaire has its associated disadvantages. Future research might include a more detailed and complete view on moral intelligence or identity development in particular might be obtained by using alternative methods such as interviews. Second, the relationship of MI and identity status and 
mental health problems might depend on cultural conditions. Third, future research needs to know why and how identity styles moral intelligence related on mental health. Finally, as the study was the first article revealing the relationship of moral intelligence and mental health problems, further research should be continuously carried out to improve and broaden the scope of relationship of two variables in university students.

\section{Summary}

In summary, the maturity and specific contents of identity may both play unique and often interactive roles in predicting boy college student health. Also, moral intelligence and identity maturity interact in predicting mental health problems of girl students. Thus, college student health might be bolstered by helping them establish appropriate moral intelligence and identity commitments. These findings provide some indications on the healthcare students that would benefit from intervention with the aim of improving their mental health problems. This can act as a guide to university administrators and enable them to understand the important of moral intelligence and maturity identity on mental health of university students. Building moral intelligence is an on-going initiative, and it is one that will always need to be at the center of what healthcare students do to promote mental health.

\section{Acknowledgements}

The authors thank the healthcare students of Babol University of Medical Sciences for participating in the study.

\section{Disclosures}

All authors state that no conflicts of interests exist.

\section{Financial Disclosure}

Islamic Azad University Tonekabon Branch.

\section{References}

[1] World Health Organization (2003) The Mental Health Problems Context: Mental Health Problems. Policy and Service Guidance Package. WHO, Geneva.

[2] Hamdan-Mansour, A.M., Halabi, J.O. and Dawani, H.A. (2009) Depression, Hostility, and Substance Use among University Students in Jordan. Mental Health Problems and Substance Use: Dual Diagnosis, 2, 52-63.

[3] Zivin, K., Eisenberg, D., Gollust, S.E. and Golberstein, E. (2009) Persistence of Mental Health Problems and Needs in a College Student Population. Journal of Affective Disorders, 117, 180-185.

[4] Yen, C.F., Hsu, C.C., Liu, S.C., Huang, C.F., Ko, C.H., Yen, J.Y. and Cheng, C.P. (2006) Relationships among Mental Health Problems Status, Social Context, and Demographic Characteristics in Taiwanese Aboriginal Adolescents: A Structural Equation Model. Psychiatry and Clinical Neurosciences, 60, 575-583. http://dx.doi.org/10.1111/j.1440-1819.2006.01561.x

[5] Dahlin, M., Joneberg, N. and Runeson, B. (2005) Stress and Depression among Medical Students: A Cross-Sectional Study. Medical Education, 39, 594-604. http://dx.doi.org/10.1111/j.1365-2929.2005.02176.x

[6] Goodwin, R.D. and Friedman, H.S. (2006) Health Status and the Five-factor Personality Traits in a Nationally Representative Sample. Journal of Health Psychology, 11, 643-654. http://dx.doi.org/10.1177/1359105306066610

[7] Wang, K.T., Yuen, M. and Slaney, R.B. (2009) Erfectionism, Depression, and Life Satisfaction: A Study of High School Students in Hong Kong. The Counseling Psychologist, 37, 249-274. http://dx.doi.org/10.1177/0011000008315975

[8] Burris, J.L., Brechting, E.H., Salsman, J. and Carlson, C.R. (2009) Factors Associated with the Psychological Well-Being and Distress of University Students. The Journal of American College Health, 57, 536-543. http://dx.doi.org/10.3200/JACH.57.5.536-544

[9] Leondari, A. and Gialamas, V. (2009) Religiosity and Psychological Well-Being. International Journal of Psychology, 44, 241-248. http://dx.doi.org/10.1080/00207590701700529

[10] Extremera, N. and Fernández-Berrocal, P. (2006) Emotional Intelligence as Predictor of Mental, Social, and Physical Health in University Students. The Spanish Journal of Psychology, 9, 45-51.

[11] Lennick, D. and Kiel, F. (2011) Moral Intelligence 2.0: Enhancing Business Performance and Leadership Success in Turbulent Times. Pearson Prentice Hall, Upper Saddle River. 
[12] Clarken, R.H. (2009) Moral Intelligence in the Schools. School of Education, Northern Michigan University, Marquette, 1-7.

[13] Belohlavek, P. (2007) The Unicist Ontology of Ethical Intelligence. Blue Eagle Group, 22.

[14] Brown, R.C.H. (2013) Moral Responsibility for (Un)Healthy Behavior. Journal of Medical Ethics, 39, 695-698. http://dx.doi.org/10.1136/medethics-2012-100774

[15] Lawler, K.A., Younger, J.W., Piferi, R.L., Jobe, R.L., Edmondson, K.A. and Jones, W.H. (2005) The Unique Effects of Forgiveness on Health: An Exploration of Pathways. Journal of Behavioral Medicine, 28, 157-167. http://dx.doi.org/10.1007/s10865-005-3665-2

[16] Quenstedt-Moe, G. and Sue, P. (2012) Forgiveness and Health in Christian Women. Journal of Religion and Health, 53, 204-216.

[17] Cox, S.S., Bennett, R.J., Tripp, T.M. and Aquino, K. (2012) An Empirical Test of Forgiveness Motives’ Effects on Employees' Health and Well-Being. Journal of Occupational Health Psychology, 17, 330-340. http://dx.doi.org/10.1037/a0028314

[18] MacBeth, A. and Gumley, A. (2012) Exploring Compassion: A Meta-Analysis of the Association between Self- Compassion and Psychopathology. Clinical Psychology Review, 32, 545-552. http://dx.doi.org/10.1016/j.cpr.2012.06.003

[19] Aghaei, H. and Khan, W. (2012) Evaluation and Comparison of Identity Style Scales and Mental Health Problems in Indian and Iranian Adolescents Females. Journal of Basic and Applied Scientific Research, 2, 11726-11731.

[20] Berzonsky, M.D. (2002) Identity Processing Styles, Self Construction, and Personal Epistemic in Assumptions: Asocial-Cognitive Perspective. The Workshop on Social Cognition Adolescence: It's Developmental Significance, Groningen.

[21] Podd, M.H. (1972) Ego Identity Status and Morality: The Relationship between Two Developmental Constructs. Dereloprnenral Psychology, 6, 497-507.

[22] Taghavi, S.R. (2002) Study Reliability and Validity of the General Health Questionnaire (GHQ). Psychology, 20, 381-397 [Persian].

[23] Aderibigbe, Y.A., Riley, W., Lewin, T., et al. (1996) Factor Structure of the 28-Item General Health Questionnaire in a Sample of Antenatal Women. The International Journal of Psychiatry in Medicine, 26, 263-269. http://dx.doi.org/10.2190/3XAV-M1BC-DA2B-DCMF

[24] Lennick, D. and Keil, F.K. (2005) Moral Intelligence. Pearson Education, Inc. Prentice Hall, Upper Saddle River, 1-7.

[25] Martin, D.E. (2010) Moral Competency Inventory Validation: Content, Construct, Convergent and Discriminant Approaches. Management Research Review, 33, 437-451. http://dx.doi.org/10.1108/01409171011041884

[26] Berzonsky, M.D. (1992) Identity Style and Coping Strategies. Journal of Personality, 60, 771-786. http://dx.doi.org/10.1111/j.1467-6494.1992.tb00273.x

[27] Ghazanfari, A. (2005) Reliability and Validity of Identity Style Inventory (ISI-6G). 2004. Journal of Psychology and Educational Studies in Education and Psychology, 4, 227-224 [Persian].

[28] Lewis, H.L. (2003) Differences in Ego Identity among College Students across Age, Ethnicity, and Gender. Identity: An International Journal of Theory and Research, 3, 159-189. http://dx.doi.org/10.1207/S1532706XID030205

[29] Mosavi, R., Akbari, Z. and Zabiholahzadeh, K. (2011) Gender Differences in Identity Dimentions among College Students. Culture, Psychotherapy, and Counseling, 8, 31-46.

[30] Beheshtifar, M., Esmaeli, Z. and Nekoie.Moghadam, M. (2011) Effect of Moral Intelligence on Leadership. European Journal of Economics, Finance and Administrative Sciences, 43, 6-11.

[31] Wood, M.S. and Fiedls, D. (2007) Exploring the Impact of Shared Leadership on Management Team Members' Job Outcomes. Baltic Journal of Management, 2, 251-272. http://dx.doi.org/10.1108/17465260710817474

[32] Gilbert, P. (2010) An Introduction to Compassion Focused Therapy in Cognitive Behavior Therapy. Journal of Cognitive Psychotherapy, 3, 97-112.

[33] Shokri, T.E.A., Daneshvarpour, Z., Ghanaee, Z. and Dastjerdi, R. (2007) Individual Difference in Identity Style Psychological Well-Being. The Role of Commitment of Identity. Cognition Scientific, 9, 33-46 [Persian].

[34] Abdizarrin, S., Sajjadian, P., Shahiad, Sh., Baianmemar, A. and Azimi, H. (2010) Relationship between Identity Style, Identity Commitment and Psychological Well-being in Guidance Girl Students in Qom City. The Journal Tolooe Behdasht, 9, 1.

[35] Berzonsky, M.D. (2003) The Structure of Identity: Commentary on Jane Kroger's View of Identity Status Transition. An International Journal of Theory and Research, 3, 231-245.

[36] Karimian, N. and Karimi, Y. (2011) The Relationship of Mental Health Problems Dimensions and Guilt Feeling with 
Marital Commitment in Married People. Journal of Family Counseling \& Psychotherapy, 1, 243-256 [Persian].

[37] Rahimi, G.R. (2011) The Implication of Moral Intelligence and Effectiveness in Organization; Are They Interrelated? International Journal of Marketing and Technology, 1, 68-73 (Persian).

[38] Hardy, S.A., Francis, S.W., Zamboanga, B.L., Kim, S.Y., Anderson, S.G. and Forthun, L.F. (2012) The Roles of Identity Formation and Moral Identity in College Student Mental Health Problems, Health-Risk Behaviors, and Psychological Well-Being. Journal of Clinical Psychology, 69, 364-382. http://dx.doi.org/10.1002/jclp.21913

[39] Nurmi, J.E., Berzonsky, M.D., Tammi, K. and Kinney, A. (1997) Identity Processing Orientation, Cognitive and Behavioral Strategies and Well-Being. International Journal of Behavioral Development, 21, 555-570.

[40] Dollinger, S.M. (1995) Identity Styles and the Five-Factor Model of Personality. Journal of Research in Personality, 29, 475-479. http://dx.doi.org/10.1006/jrpe.1995.1028

[41] Adams, G.R., Munro, B., Doherty-Poirer, M., Munro, G., Petersen, A.M.R. and Edwards, J. (2001) Diffuse-Avoidance, Normative, and Informational Identity Styles: Using Identity Theory to Predict Maladjustment. Identity: An International Journal of Theory and Research, 1, 307-320. http://dx.doi.org/10.1207/S1532706XID0104_01

[42] Jones, R.M., Ross, C.N. and Hartmann, B.R. (1992) An Investigation of Cognitive Style and Alcohol/Work-Related Problems among Naval Personnel. Journal of Drug Education, 22, 241-251.

http://dx.doi.org/10.2190/3HE9-TCAE-2P3Y-BN5H 